ISSN 1420-3049

http://www.mdpi.org

\title{
A New Synthetic Route to Dihydrobenzopyran Via Tandem Demethylation Cyclisation
}

Geetha Gopalakrishnan $^{1 *}$, Viswanathan Kasinath ${ }^{1}$, N.D. Pradeep $\operatorname{Singh}^{1}$, R. Thirumurugan ${ }^{2}$, S. Shanmuga Sundara Raj $^{3}$ and G. Shanmugam ${ }^{2}$

${ }^{1}$ Centre for Natural Products, SPIC Science Foundation, Guindy, Chennai 600 032, India

Tel.: 044-235-1903, Fax: 044-235-1504, E-mail: geethagopal@ hotmail.com

${ }^{2}$ Department of Crystallography and Biophysics, University of Madras, Guindy Campus, Chennai-600 025 , India

${ }^{3}$ X-ray Crystallography Unit, School of Physics, Universiti Sains Malaysia, 11800 USM,Penang, Malaysia

Received: 17 April 2000 / Accepted: 26 May 2000 / Published: 16 June 2000

\begin{abstract}
A tandem demethylation-cyclisation reaction resulting in the formation of pyran rings using $\mathrm{AlCl}_{3} / \mathrm{EtSH}$ reagent under mild reaction conditions is reported. X-ray diffraction studies on the intermediate support the suggested mechanism.
\end{abstract}

Keywords: Osthol, pyranocoumarins, demethylation, cyclisation, hard-soft interactions.

\section{Introduction}

In our continuing search for bio-active leads from natural products, a coumarin analog, osthol 1 [1] and its derivatives were considered, since they are known to exhibit anti-inflammatory and antiproliferatory activities[2]. While attempting to prepare a pyrano coumarin analog from osthol, a simple and convenient method for preparing the same was noted while the reported procedures failed to give the desired product in good yields.

Dihydrobenzopyrans are synthesised from phenols and isoprene in the presence of $\mathrm{AlCl}_{3}$ [3] or phenols having isoprene units in the 2-position, in the presence of PTSA[4]. Allyl phenols undergo cyclisation to yield dihydrobenzopyrans, in the presence of phospate esters [5] or metal carbonyls [6] or zeolites [7] under high temperatures. Synthesis of dihydrobenzopyrans from aromatic ethers having isoprenyl group in 2-position involves either harsh acid conditions like refluxing with $\mathrm{HBr} / \mathrm{AcOH}$ overnight [8] or multi step synthesis [9].

(C) 2000 by MDPI (http://www.mdpi.org). Reproduction is permitted for noncommercial purposes. 


\section{Results and Discussion}

The use of $\mathrm{AlCl}_{3} / \mathrm{EtSH}$ reagent [10] for demethylation of aromatic ethers has been reported. However, treatment of osthol with $\mathrm{AlCl}_{3} / \mathrm{EtSH}$ at room temperature resulted in direct cyclisation by transetherification reaction yielding pyrano coumarin, 3. Reaction of osthol with $\mathrm{AlCl}_{3}$-DMS complex yielded the demethylated product osthenol (4) [11] (Scheme-I).<smiles>COc1ccc2ccc(=O)oc2c1CC=C(C)C</smiles>

(1)

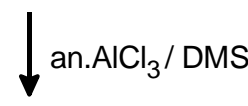<smiles>CC(C)=CCc1c(O)ccc2ccc(=O)oc12</smiles>

(4)<smiles>CCC(C)(C)CCc1c(O)ccc2ccc(=O)oc12</smiles>

(2)<smiles>C[14CH][14CH]</smiles>

NO CYCLISATION

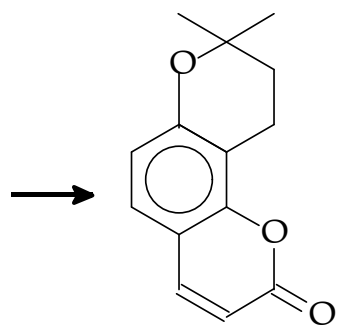

(3)

\section{Scheme 1.}

It is noteworthy to mention that no cyclisation was observed while using other Lewis acid-ethane thiol complexes namely, $\mathrm{ZnCl}_{2} / \mathrm{EtSH}, \mathrm{BF}_{3} . \mathrm{OEt}_{2} / \mathrm{EtSH}$ and $\mathrm{TiCl}_{4} / \mathrm{EtSH}$ under different conditions. (Tab.1).

Table 1. Reactions of osthol.

\begin{tabular}{|c|c|c|c|c|}
\hline S.No & Reagents & Time(h) & Product $^{\mathrm{c}}$ & Yield(\%) $^{\mathrm{c}}$ \\
\hline 1. & $\mathrm{BF}_{3} \cdot \mathrm{OEt}_{2} / \mathrm{EtSH}$ & $48^{\mathrm{a}}$ & - & - \\
\hline 2. & $\mathrm{AlCl}_{3} / \mathrm{EtSH}$ & $12^{\mathrm{b}}$ & $\mathbf{2}$ & 40 \\
& & & $\mathbf{3}$ & 20 \\
\hline 3. & $\mathrm{AlCl}_{3} / \mathrm{EtSH}$ & $24^{\mathrm{b}}$ & $\mathbf{3}$ & 76 \\
\hline 4. & $\mathrm{HBr} / \mathrm{AcOH}$ & 12 & $\mathbf{3}$ & 40 \\
\hline 5. & $\mathrm{AlCl}_{3} / \mathrm{DMS}$ & $24^{\mathrm{b}}$ & $\mathbf{4}$ & 62 \\
\hline 6. & $\mathrm{ZnCl}_{2} / \mathrm{EtSH}$ & $48^{\mathrm{a}}$ & $\mathbf{4}$ & 24 \\
\hline 7. & $\mathrm{TiCl}_{3} / \mathrm{EtSH}$ & $48^{\mathrm{a}}$ & - & - \\
\hline 8. & $\mathrm{TiCl}_{4} / \mathrm{EtSH}$ & $48^{\mathrm{a}}$ & - & - \\
\hline
\end{tabular}

${ }^{\mathrm{a}}$ reflux $;{ }^{\mathrm{b}}$ room temperature stirring; ${ }^{\mathrm{c}}$ In all these reactions a certain amount of diethyldisulphide was formed and it was maximum in the reaction with $\mathrm{TiCl}_{4} / \mathrm{EtSH}$. 
In the case of $\mathrm{AlCl}_{3} / \mathrm{EtSH}$, the reactive species, $\mathrm{Al}(\mathrm{SEt})_{3}$, has a pronounced hard-hard interaction resulting in demethylation followed by cyclisation, compared to other Lewis acids. Both the nucleophilicity of the phenoxy oxygen and the presence of a good leaving group at the appropriate position in the intermediate complex (V) seems to influence the cyclisation reaction. Both these factors are satisfied when $\mathrm{AlCl}_{3} / \mathrm{EtSH}$ is used. The intermediate 2, which has been isolated and crystallised, underwent cyclisation only in the presence of $\mathrm{AlCl}_{3} / \mathrm{EtSH}$ and not with $\mathrm{AlCl}_{3}$ alone. The X-ray diffraction data obtained on the intermediate II confirmed its structure (Fig-1).

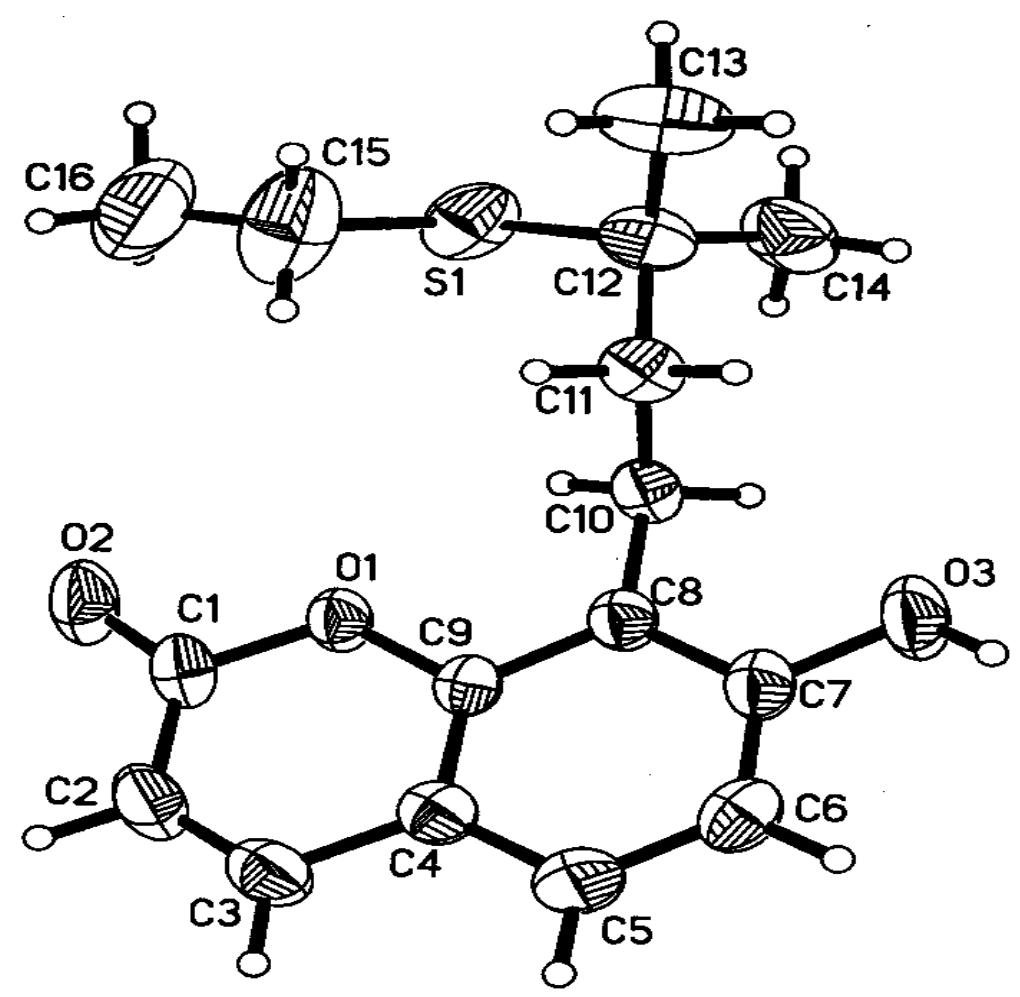

Figure 1.

These observations prove the fact that nucleophilicity of the phenoxy oxygen is increased in the complex 5 compared to that of the oxygen in the complex $\mathbf{6}$.<smiles>CCCCC(C)(C)CCc1c(OCCC)ccc2ccc(=O)oc12</smiles>

(5)<smiles>CCOc1ccc2ccc(=O)oc2c1CCC(C)(C)SCCCl</smiles>

(6 )

Scheme 2. 
The need for the good leaving group is demonstrated by the reaction of osthol with $\mathrm{AlCl}_{3}$-DMS complex. Though the nucleophilicity of the phenoxy oxygen is the same as in the reaction with $\mathrm{AlCl}_{3} / \mathrm{EtSH}$, cyclisation is not observed in the former reaction due to the lack of good leaving group.

\section{Experimental}

\section{General}

Melting points were determined using a Toshniwal (India) apparatus and are uncorrected. Both ${ }^{1} \mathrm{H}$ and ${ }^{13} \mathrm{C}$-NMR spectra were recorded with a BRUKER DPX-200 MHz instrument using $\mathrm{CDCl}_{3}$ as solvent and TMS as internal standard. Mass spectra were recorded in Shimadzu QP-5000 instrument.

\section{7-Hydroxy-8-(3-methyl-3-thioethylbutyl)-coumarin (2)}

To a magnetically stirred supension of anhydrous $\mathrm{AlCl}_{3}(0.33 \mathrm{~g}, 2.5 \mathrm{mmol})$ in $\mathrm{CH}_{2} \mathrm{Cl}_{2}(5 \mathrm{~mL})$ at $0^{\circ} \mathrm{C}$ was added ethanethiol $(2.0 \mathrm{~mL})$ followed by osthol $1(0.24 \mathrm{~g}, 1.0 \mathrm{mmol})$ in $\mathrm{CH}_{2} \mathrm{Cl}_{2}(3 \mathrm{~mL})$ added dropwise over a period of $10 \mathrm{~min}$. The temperature of the reaction mixture was allowed to raise to room temperature $\left(30^{\circ} \mathrm{C}\right)$ and stirring continued $(12 \mathrm{hrs})$. The reaction was quenched with cold dilute $\mathrm{HCl}(10 \mathrm{~mL})$ and extracted with $\mathrm{CH}_{2} \mathrm{Cl}_{2}(2 \times 15 \mathrm{~mL})$. Removal of the solvent yielded a dark viscous gum, which on column chromatography (silica gel, 60-120 mesh) with 95:5 hexane: ethyl acetate furnished the cyclised product $3(0.04 \mathrm{~g}, 20 \%)$. Further elution of the column with 90:10 hexane : ethyl acetate yielded the demethylated compound $\mathbf{2}$ as a solid which was recrystallised from ethyl acetate. (0.11 g, 40\%). m.p-112-114 ${ }^{0} \mathrm{C}$.

${ }^{1} \mathrm{H}-\mathrm{NMR}(\delta, \mathrm{ppm}): 1.25(\mathrm{t}, 3 \mathrm{H}, \mathrm{J}=7.4 \mathrm{~Hz}), 1.30(\mathrm{~s}, 6 \mathrm{H}), 1.67(\mathrm{bs}, 1 \mathrm{H}), 1.81(\mathrm{t}, 2 \mathrm{H}, \mathrm{J}=7.4 \mathrm{~Hz}), 2.53$ $(\mathrm{q}, 2 \mathrm{H}, \mathrm{J}=7.4 \mathrm{~Hz}), 2.95(\mathrm{t}, 2 \mathrm{H}, \mathrm{J}=7.3 \mathrm{~Hz}), 6.25(\mathrm{~d}, 1 \mathrm{H}, \mathrm{J}=9.4 \mathrm{~Hz}), 6.85(\mathrm{~d}, 1 \mathrm{H}, \mathrm{J}=8.3 \mathrm{~Hz}), 7.25(\mathrm{~d}, 1 \mathrm{H}$, $\mathrm{J}=8.3 \mathrm{~Hz}), 7.65(\mathrm{~d}, 1 \mathrm{H}, \mathrm{J}=9.4 \mathrm{~Hz})$.

${ }^{13}$ C-NMR: $14.2,18.8,22.1,28.8,40.7,46.5,112.3,112.5,113.3,116.3,126.4,144.1,157.7 . \mathrm{MS}$ (EI, m/z) $292\left(\mathrm{M}^{+}\right)$.

Crystal data

$\mathrm{C}_{16} \mathrm{H}_{20} \mathrm{O}_{3} \mathrm{~S}, \mathrm{M}=292.38$, monoclinic, $\mathrm{a}=8.4325(1), \mathrm{b}=10.8293(1), \mathrm{c}=17.8545(1) \AA, \quad \beta=101.565(1)^{\circ}$, $\mathrm{U}=1597 \AA$, $\mathrm{T}=293 \mathrm{~K}$, space group $\mathrm{P} 21 / \mathrm{n}, \mathrm{Z}=4$,

$\mathrm{D}_{\mathrm{c}}=1.216 \mathrm{Mg}^{-3}, \mu=0.207 \mathrm{~mm}^{-1}, \mathrm{~F}(000)=624$, crystal dimensions $0.48 \times 0.34 \mathrm{x} 0.32 \mathrm{~mm}$. Of the 12378 reflections collected by a Siemens SMART CCD area detector diffractometer with graphite monochromated Mo-K $\alpha$ radiation $\left(\lambda=0.71073 \AA\right.$ ) between 2.21 to $28.29^{\circ},-11<\mathrm{h}<7,-14<\mathrm{k}<14$, $20<1<23,3901$ were independent $\left(\mathrm{R}_{\text {int }}=0.054\right)$ and 2966 were considered and observed. 
Structure solution and refinement

The crystal structure was solved by direct methods (SHELXS-97) [12] and refined anisotropically by full matrix least-squares on $|\mathrm{F}|^{2}$ (SHELXL-97) [13]. Most of the $\mathrm{H}$-atoms were located in a difference map and refined freely with isotropic displacement parameters. The final $\mathrm{R}$ indices were $\mathrm{R}=4.41 \%$ for observed reflections and $\mathrm{w} R\left(\mathrm{~F}^{2}\right)=12.76 \%$ for all data. The final difference map extremes were +0.315 and -0.364 e $\AA^{-3}$, and the final shift/esd was 0.001 .

\section{7,8-(11,11-Dimethyl pyrano)coumarin (3)}

The above reaction was quenched after $24 \mathrm{hrs}$. Usual workup and purification of the crude product by column chromatography (silica gel, 60-120 mesh, 95:5 hexane : ethyl acetate) yielded the title compound as a colourless crystalline solid. $(0.17 \mathrm{~g}, 76 \%)$. m.p-101-103 ${ }^{0} \mathrm{C}$.

${ }^{1} \mathrm{H}-\mathrm{NMR}:(\delta, \mathrm{ppm}) 1.38(\mathrm{~s}, 6 \mathrm{H}), 1.85(\mathrm{t}, 2 \mathrm{H}, \mathrm{J}=6.8 \mathrm{~Hz}), 2.90(\mathrm{t}, 2 \mathrm{H}, \mathrm{J}=6.8 \mathrm{~Hz}), 6.21(\mathrm{~d}, 1 \mathrm{H}, \mathrm{J}=9.3$ $\mathrm{Hz}), 6.75(\mathrm{~d}, 1 \mathrm{H}, \mathrm{J}=8.6 \mathrm{~Hz}), 7.25(\mathrm{~d}, 1 \mathrm{H}, \mathrm{J}=8.6 \mathrm{~Hz}), 7.65$ (d, 1H, J=9.3 Hz).

${ }^{13} \mathrm{C}-\mathrm{NMR}:(\delta, \mathrm{ppm}) 16.4,26.6,31.5,75.6,109.3,111.5,111.9,114.4,119.5,126.2,144.0,153.2$, 157.5, 161.6. Mass (EI, m/z) $230\left(\mathrm{M}^{+}\right)$.

\section{Osthenol (4)}

Dimethyl sulphide $(2.5 \mathrm{ml})$ was added dropwise to a suspension of anhydrous $\mathrm{AlCl}_{3}(0.33 \mathrm{~g}, 2.5$ mmol) in $\mathrm{CH}_{2} \mathrm{Cl}_{2}(5 \mathrm{~mL})$ at $0^{\circ} \mathrm{C}$ with stirring to yield a completely dissolved $\mathrm{AlCl}_{3} / \mathrm{DMS}$ solution. To this solution, osthol $1(0.24 \mathrm{~g}, 1.0 \mathrm{mmol})$ in $\mathrm{CH}_{2} \mathrm{Cl}_{2}(3 \mathrm{~mL})$ was added over a period of 10 min.at the same temperature. Then the reaction mixture was allowed to raise to room temperature $\left(30^{\circ} \mathrm{C}\right)$ and stirring continued $(24 \mathrm{hrs})$. The reaction mixture was quenched with cold $1 \mathrm{~N} \mathrm{HCl}(10 \mathrm{~mL})$ and extracted with $\mathrm{CH}_{2} \mathrm{Cl}_{2}(2 \times 15 \mathrm{~mL})$. Purification of the crude product by column chromatography yielded osthenol (4) [11] $(0.14 \mathrm{~g}, 62 \%)$.

Acknowledgements: We wish to thank Prof. T.R. Govindachari for a sample of osthol, and one of the authors (VK) thanks CSIR, New Delhi, Government of India for a Research Fellowship.

\section{References and Notes}

1. CAS-[484-12-8]

2. Liu, J.H.; Zschocke, S.; Reininger, E.; Bauer, R. Inhibitory effects of Angelica Pubescens f. biserrata on 5-Lipoxygenase and Cycloxygenase. Planta Medica 1998, 64, 525-529.

3. Bolzoni, L.; Casiraghi, G.; Casnati, G.; Sartori, G. Selectivity in reactions between metal phenoxides and isoprene: Facile synthesis of 2,2-dimethyl chromans. Angew. Chem. Int. Ed. Engl 1978, 17, 684-686. 
4. Govindachari, T.R.; Kalyanaraman, P.S.; Muthukumaraswamy N.; Pai, B.R. Xanthones of Garcinia Mangostana linn. Tetrahedron 1971, 3919-3926.

5. Miller, J.A.; Wood, H.C.S. Phosphate esters. Part I. The synthesis of phenolic isoprenoids from Allylic phosphates. J. Chem. Soc.(C) 1968, 1837-1843.

6. Bernard, A.M.; Cocco, M.T.; Onnis, V.; Piras, P.P. Facile Synthesis of 2,2-dimethyl chromans by $\mathrm{Mo}(\mathrm{CO})_{6}$. Synthesis 1998, 256-258.

7. Biggi, F.; Carloni, S.; Maggi, R.; Muchetti, C.; Rastelli, M.; Sartori, G. Reaction between phenols and isoprene under zeolite catalysis - Highly selective synthesis of chromans and o-isopentenylphenols. Synthesis 1998, 301-304.

8. Nilson, J.L.G.; Sievertsson, H.; Selander, H. Synthesis of methyl substituted 6-hydroxychromans, model compounds of tocopherols. Acta. Chem. Scand. 1968, 22, 3160-3170.

9. Richards, R.W.; Ronneberg, H. Synthesis of (-)- $\Delta^{9}-6 \mathrm{a}, 10 \mathrm{a}-\mathrm{trans}$ tetrahydrocannabinol - $\mathrm{BF}_{3}$ catalyzed arylation by a homo cuprate. J. Org. Chem. 1984, 49, 572-573.

10. Node, M.; Nishide, K.; Fuji, K.; Fujita, E. Hard acid and soft nucleophile system. 2. Demethylation of methyl ethers of alcohol and phenol with an aluminium halide-thiol system. J. Org. Chem. 1980, 45, 4275-4277.

11. CAS [484-14-0]

12. G.M.Sheldrick, SHELXS-97, University of Gottingen, Germany, 1997

13. G.M.Sheldrick, SHELXL-97, University of Gottingen, Germany, 1997.

Samples Availability: Available from MDPI.

(C) 2000 by MDPI (http://www.mdpi.org). Reproduction is permitted for noncommercial purposes. 